IOSR Journal of Pharmacy

e-ISSN: 2250-3013, p-ISSN: 2319-4219, www.iosrphr.org

Volume 2 Issue 6 || || Nov-Dec. 2012 ||| PP.42-48

\title{
Tobacco cessation to lead healthy life! Let's take a stand and banish this evil from our lives
}

\author{
Raaz Maheshwari ${ }^{1}$, Rajesh Kumar Yadav ${ }^{2}$, A K Chauhan ${ }^{3}$ \\ Vikram Chauhan ${ }^{4}$, Bina Rani ${ }^{5}$, Shobha Sharma ${ }^{4}$ \\ 1. Department of Chemistry, SBRMGC, Nagaur, Rajasthan, India \\ 2. Department of Environmental Science, SS Jain Subodh PG \\ College, Jaipur, Rajasthan \\ 3. Department of Chemistry, SKGC, Sikar, Rajasthan \\ 4. Department of Botany, SBRMGC, Nagaur, Rajasthan \\ 5. Department of Engineering Chemistry \& Environmental Engineering, \\ PCE, Sitapura, Jaipur, Rajasthan \\ 6. Department of Chemistry, JNVU, Jodhpur, Rajasthan.
}

Tobacco use is one of the biggest public health threats the world ever faced. There are over 4,000 chemicals in a cigarette, 40 of which are carcinogenic. Nicotine, tar, hydrogen cyanide (HCN), volatile aldehydes, and nitrosamines are some of the hazardous substances in the tobacco smoke. The most effective preventive measure is to avoid use. Cancer killed 5,56,400 people across the country last year and it is alarming to know that India has more than 300 million smokers. Five million of them are children and at least 55,000 children take to tobacco every year. More people die of tobacco every year than alcohol. AIDS, car accidents, drug over dose, murders and suicides put together, claimed health experts on the eve of World No Tobacco Dar 2012.
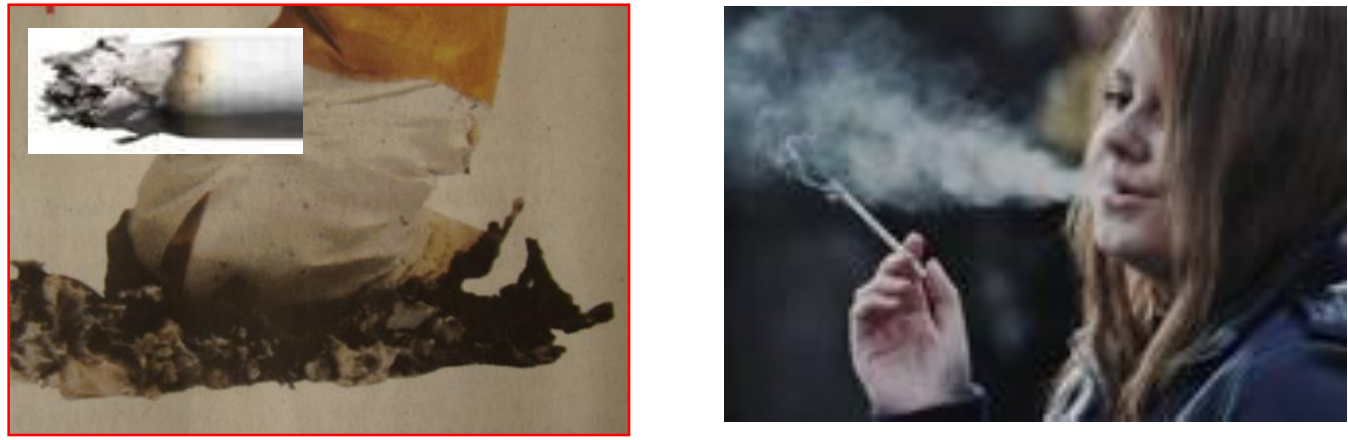

[Smoking-related disease is snatching our beloved family members and friends away from us at an alarming rate. According to the World Health Organization, smoking related-diseases kill one in 10 adults globally, causing four million deaths a year. While some of the accounts in this section are heartbreaking and difficult to read, they are stark reminders of what may well lie ahead of us if we don't stop smoking. My heartfelt thanks go out to all who have shared their very personal and often painful stories here with us in the effort to help save lives...your life, dear reader. The ingredients and additives in cigarettes were largely unknown until 1994, when five major tobacco manufacturers in the United States submitted a long list of ingredients that were used in the production of American cigarettes.]
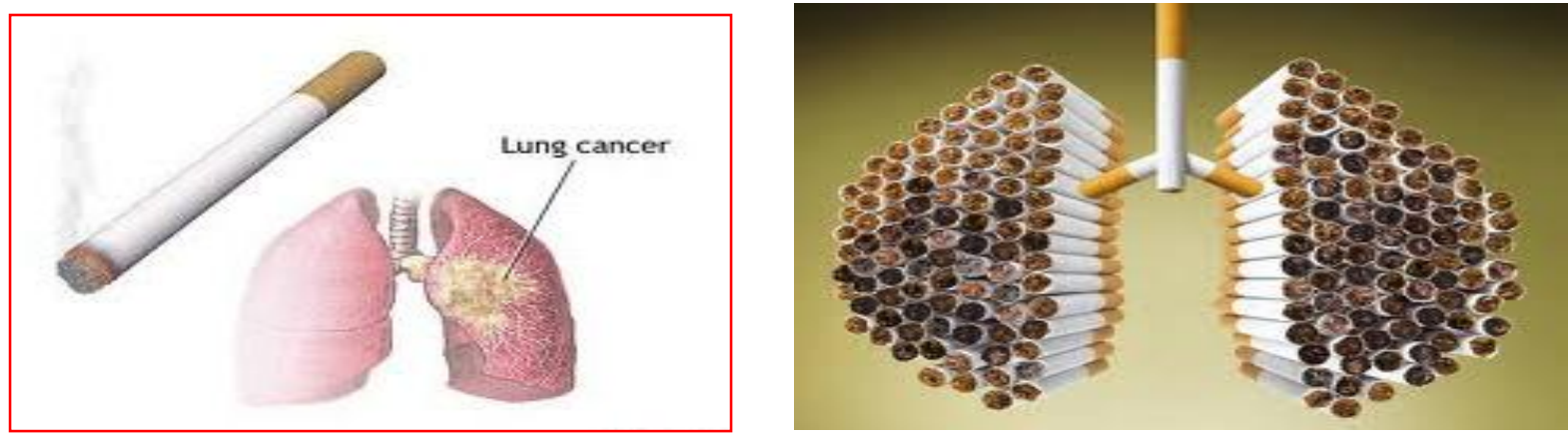
Tobacco use is one of the leading preventable causes of death. The use of tobacco causes disorders of lungs, blood, and heart and affects fertility. It is because of tobacco consumption, the risk of TB increases by 2 $3 \mathrm{x}$, pulmonary diseases by $2 \mathrm{x}$, strokes $1.6 \mathrm{x}$, cancer by $2.1 \mathrm{x}$ and the risk of other diseases by $1.7 \mathrm{x}$. Heart expert claimed that the use of tobacco could increase risk of heart attack by 2-3x. The nicotine in tobacco is responsible for swelling in aorta, shrinking of nerves and certain cases it may burst too. Tobacco's deadly substance, as soon as gets into the system, it increases the release of dopamine in the brain. Dopamine helps in relaxing the nerves. Heart, brain and the central nervous system becomes more active as soon as its secretion increases in brain. A person gets addicted when this secretion is increased repeatedly with the usage of cigarettes, gutka or other variants of tobacco. In cases of addition, a person experiences restlessness, anger, disappointment and headache for want of tobacco.

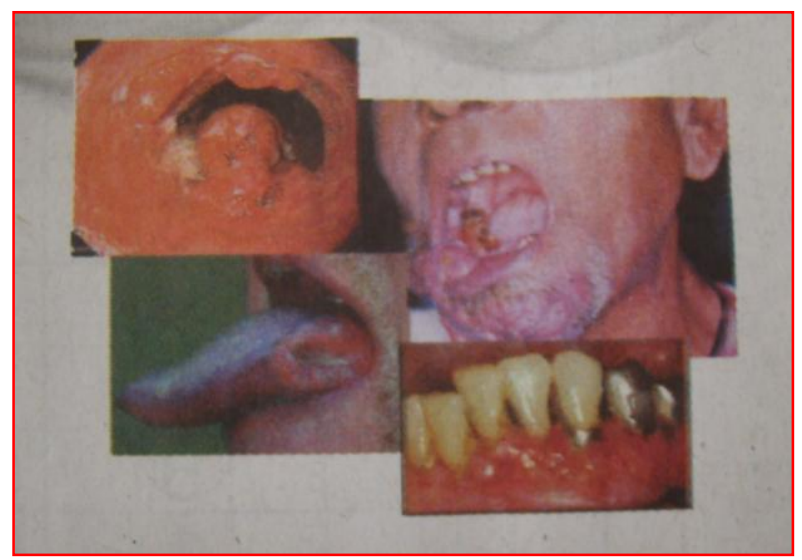

Oral Cancer: There are twice as many deaths as a result of oral cancer - thanks to tobacco chewing compared to lung cancer. Rural men are twice more likely to die from tobacco-related cancers, compared to urban men in India. The top five or six cancers in men are tobacco-related: that of lung, oral cavity, larynx, oesophagus and pharynx. In women, types of cancer that occur due to tobacco use are cancers of the cervix, oral cavity, oesophagus and lung. Combining alcohol with cigarettes increases risk of oral cancer, and of cancer of the larynx and oesophagus. Tobacco products produce changes in all of the cells that are exposed. Thus, the entire oral cavity, lungs and larynx are at risk for developing tumours. This can be completely prevented by simple changes in lifestyle and regular screening.

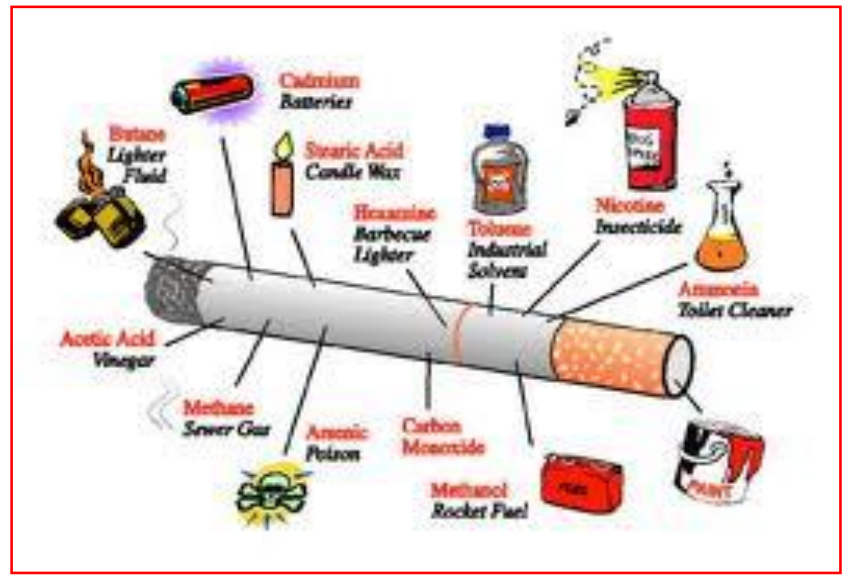

Destroy the Habit of Gutka: the Indian Cancer Cavity (ICC) states this high prevalence of oral cancer in India is primarily because of smokeless tobacco - gutka, quid, snuff, misri. Tobacco, when kept in the mouth, leaches out carcinogens, which act on oral mucosa causing neoplastic changes. Tobacco chewers and smokers may develop white or reddish patches in the mouth called leukoplakia or erythroplakia. They report limited mouth opening and burning sensation on eating spicy food. Oral submucous fibrosis is a progressive lesion in which the opening of the mouth becomes difficult, it occurs in people who use supari or areca nut with or without tobacco. It is not necessary that tobacco alone causes cancer but supari can produce submucous fibrosis, a premalignant condition with high incidence of conversion to cancer.

Chewing paan can cause oral cancer Chewing betel quid or paan exposes half a billion people to substances that act as direct carcinogens in the mouth, scientists have revealed. Mu-Rong Chao and ChiungWen Hu explained that betel quid (BQ) consists of nuts from the arcea tree, sometimes combined with spices, such as cardamom or saffron, and other ingredients like slaked lime. Available in commercial forms, BQ is 
popular among people in China, India and other Asian countries, and people of Asian heritage living in the U.S. and other countries. Researchers have known for decades that chewing BQ can lead to oral cancer, and showed recently that the substances in $\mathrm{BQ}$ could be changed into carcinogens in the body. The researchers explored whether there were any substances in the arcea nut that can cause cancer directly, without any need for the body to change or "activate" them. They discovered that compounds in the arcea nut can "alkylate" the genetic material DNA, causing changes that increase the

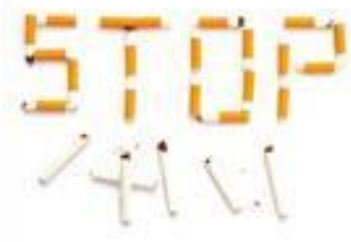
risk of cancer, and they are present in betel quid in amounts high enough to do so."Our study showed that these alkylating agents are present at levels sufficient to cause DNA damage and could potentially have adverse implications to human health, particularly in the case of the development of oral cancer for BQ chewers," they said. Researchers reported in ACS' journal Chemical Research in Toxicology. Chewing paan can cause oral...

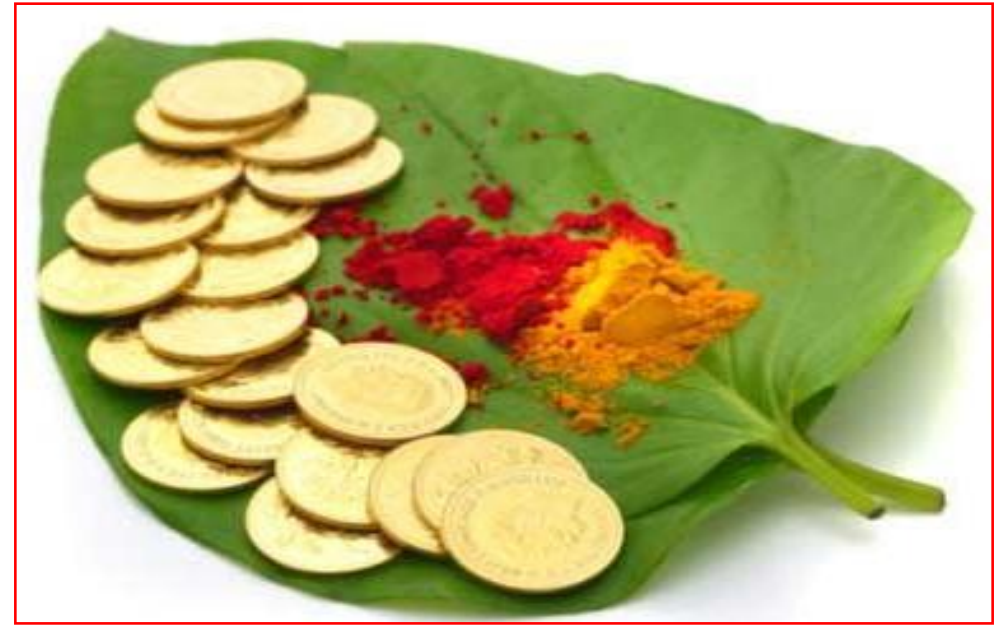

\section{Nicotine Gum \& Skin Patch Face Doubts}

The nicotine gum and patches that millions of smokers use to help kick their habit have no lasting benefit and may backfire in some cases, according to the most rigorous long-term study to date of so-called nicotine replacement therapy. The study published in the journal Tobacco Control, included nearly 800 people trying to quit smoking over a period of several years, and is likely to inflame a long-running debate about the value of nicotine alternatives. In medical studies, the products have proved effective, making it easier for people to quit, at least in the short term. Those earlier, more encouraging findings were the basis for federal guidelines that recommended the products for smoking cessation. But in the surveys, smokers who have used the over-thecounter products, either as part of a program or on their own, have reported little benefit from them.NYT NEWS

\section{JHUNJHUNU FISRT SMOKE-FREE DISTRICT IN STATE}

Jhunjhunu on World No Tobacco Day earned the distinction of being the first smoke-free district in the state. Now, if any person is caught smoking at public places in Jhunjhunu, he or she would be challenged. The public places include railway station, bus stands, banks, government offices, schools, colleges and other public places. The district administration has dedicated certain places where a person can smoke. We have declared Jhunjhunu as a smoke-free district. We have followed all the rules and guidelines mentioned under Control of Tobacco Product Law (CIPTA) 2003,“ Jhujhunu district collector stated. The COTPA prohibits smoking in public places. Under the Act, if anyone flouts the rules, a fine of Rs 200 is imposed To declare the district smoke-free, Jhunjhunu district administration displayed boards at entrances of every government building. As per Act, restaurants and hotels should also be smoke-free as they are also public places. The district administration put up boards saying "No Smoking Area - Smoking here is an offence." "We have authorized our officers to challen persons smoking in public places," Collector stated.

Activists urge govt to ban gutka: Various social organizations on World No Tobacco Day, $31^{\text {st }}$ May, 2012, sent a memorandum to the chief minister demanding a ban on gutka in the state. Organizations such as Gayatri Shakti Peet Vatika (GSPV), Jamat-e-Islami Hind (JIH), Indian Asthma Care society (IACS), Rajasthan Jan Manch (RJM), Welfare Party of India (WPI), Rajasthan, Volunteer Health Association (VHA), and Jain Samiti (JS) took part in signature campaign against tobacco on World No Tobacco Day and also held Sadbuddhi Yagya at Badi Chauper. Nukked nataks were also held on this auspicious day and the activists burnt an effigy of gutka consuming person. "Many states have banned gutka. The state government should not think about income 
from gutka products and ban it for the sake of health of the people," stated state secretary of the Welfare Party of India (Rajasthan).

\section{DIAL TO QUIT}

Nicorette, manufacturer of tobacco cessation products, announced the launch of a National Tobacco Cessation Quit Line-1800 227787 to mark the World No Tobacco Day. The national quit line is dedicated tollfree number that can be reached daily from 9am to $9 \mathrm{pm}$ from May 31 onwards. The quit line will provide free support and guidance to tobacco users to overcome their addition and increase their chances of quitting successfully. This quit line is designed to help tobacco users by answering their queries, formulating a personalized quit plan depending upon their tobacco consumption pattern (cigarettes, beedis and other forms of chewing tobacco) and supporting them through the entire 12 week journey of quitting tobacco through a combination of phone calls, text messages, emails and hand deliveries.

Callers will receive tobacco cessation counselling in English, Marathi, Gujarati, Hindi and Bengali. This free of charge service can be used by all tobacco users, friends and even healthcare practitioners seeking to provide tobacco cessation therapy for their patients. To support the telephone counselling, callers wanting onground support will be referred to local Tobacco Intervention Initiative (TII) centre of the Indian Dental Association (IDA). At each centre, dentists trained in tobacco cessation will help tobacco users give up their addiction and improve their health. Currently there are 500 TII centres across India. Studies show that proactive telephone counselling is an effective intervention for tobacco cessation and achieves 56 per cent increase in quit rates as compared to self-help, since a large number of tobacco users want to quit but do not know how to do it effectively. The World Health Organization (WHO) recommends quitlines as an essential part of any tobaccocontrol-effort since they are easily accessible, cost-effective and proven tools to increase the quit success rate.

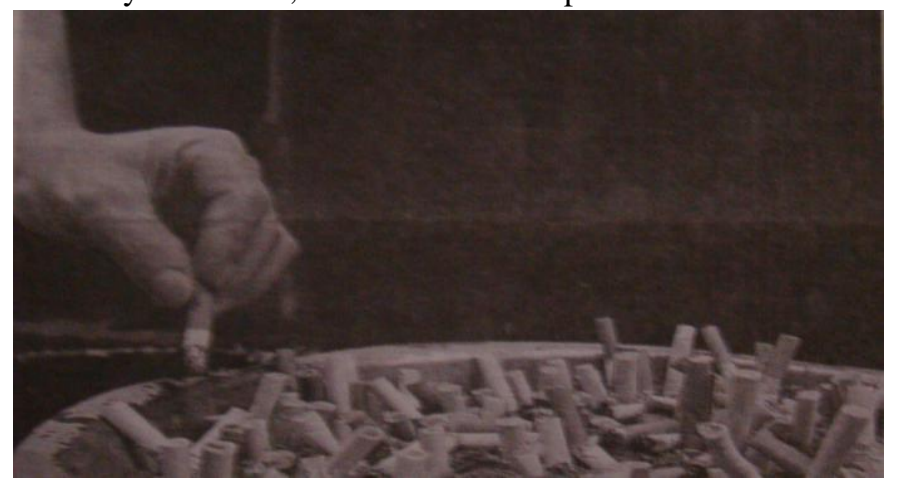

Vice President Marketing, Consumer Division, Johnson \& Johnson, India states, "We want to partner with quitters through their entire journey by providing them the entire infrastructure and support that is needed to quit. The quit line is the latest addition to Nicorette's tobacco cessation infrastructure that consists of an active Facebook page and a text-to-quit service." The global Adult Tobacco Survey (2009-2010) shows that one third of all adults in India use tobacco in some form or the other and over 35 per cent of them want to quit this habit. However, inaccessibility to treatment, lack of support and low levels of awareness has been the major hindrances in determining low success rates. Nicorette is a stop-tobacco quit aid in the form of sugar free nicotine gum. It helps to reduce nicotine cravings that make quitting tobacco so hard. Nicorettem based on the principal of Nicotine Replacement Therapy (NRT), is nicotine bound to a sugarless chewing gun base. It provides therapeutic (clean) nicotine slowly and in lesser quantities that what a cigarette or chewing tobacco provides but also just enough to satisfy the cravings. Unlike chewing tobacco and cigarette smoke, it delivers nicotine which is devoid of any harmful chemicals like tar, irritants, carbon dioxide and nitrosamines and hence is safer,

Delhi Prohibition of Smoking and non-smokers' health protection act, 1996 and cigarettes and other tobacco product act, 2003 bans smoking in enclosed public places, prohibits sale of tobacco products to and by minors or sale of tobacco products with 100 meters of educational institutions, advertising of tobacco products and makes it mandatory to display health warning pictorially on packs of tobacco products.

\section{WOMEN CAN ADD NINE YEARS TO THEIR LIVES BY QUITTING SMOKING BEFORE THE AGE OF 40 BUT STILL FACE A 20 PER CENT HIGHER DEATH RATE THAN THOSE WHO NEVER SMOKED, A STUDY SAYS.}

Published in The Lancet, a survey of nearly 1.2 million women in Britain showed that smoking throughout adulthood chopped on average 11 years off life span. These results echoed the findings of earlier research conducted on men. Among women who kicked the habit before the age of 40, the researchers measured 
an average life span gain of more than nine years compared with those who never stopped. For those who quit before 30 the gains were even bigger - about 10 years."Whether they are men or women, smokers who stop before reaching middle age will on average gain about an extra 10 years of life," study co-author Richard Peto of the University of Oxford said. A female smokers study reveals the habit can shorten life by 10 years, but quitting early can almost eliminate the risk.

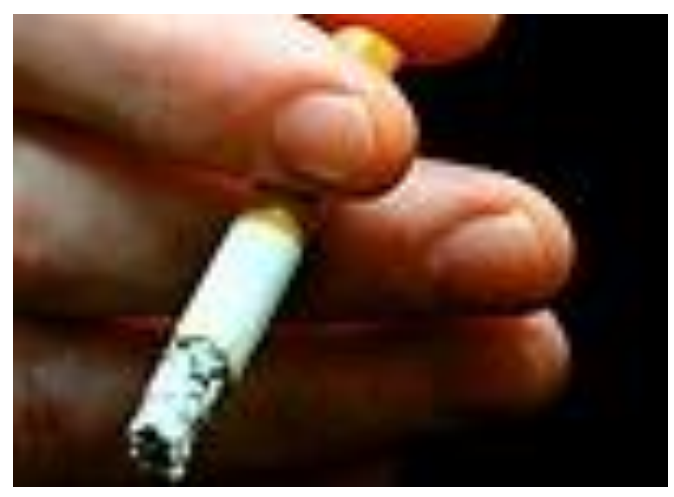

Quitting smoking early slashes risks

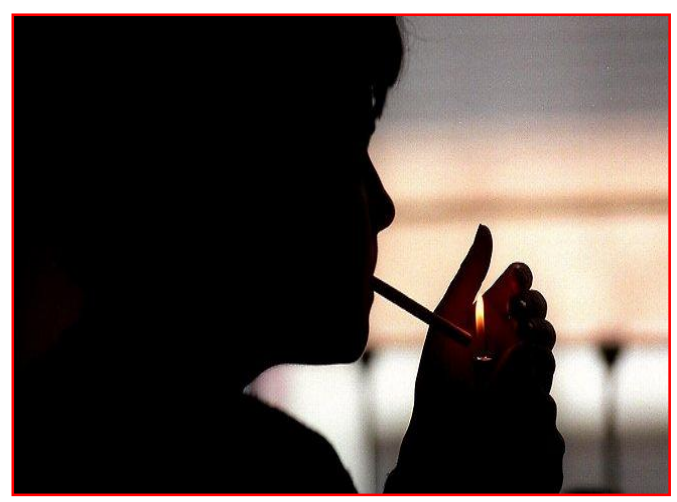

\section{Its official - smoking makes men stupid}

Researchers have found smoking reduces cognition skills and increases memory loss. But only in men, not women. Australian experts say an international study that suggests people who quit smoking gain about $5 \mathrm{~kg}$ in a year doesn't apply to all smokers. But the paper warned this did not mean that it was safe to continue smoking until 40 before quitting."Women who do so have throughout the next few decades (of their lives) a mortality rate 1.2 times that of never-smokers. This is a substantial excess risk, causing one in six of the deaths among these ex-smokers."In Europe and the United States, the popularity of smoking reached its peak among women in the 1960s, decades later than for men. The Lancet study is one of the most extensive probes into the impacts of smoking on this generation of women, the first likely to have smoked substantially throughout their adult lives. The research is part of a vast survey that enrolled 1.2 million women in the UK between 1996 and 2001. The volunteers were asked to detail their smoking history, and were followed for an average of 12 years.

The women were on average 55 years old when they signed up. Twenty per cent of them were smokers, 28 per cent ex-smokers, while 52 per cent had never smoked. The researchers found that the group of women who continued smoking had three times the overall mortality rate of never-smokers. While the risks increased with the amount smoked, "Even those smoking fewer than 10 cigarettes per day ... had double the overall mortality rate than never-smokers," warned the study. It also cautioned against so-called "light" cigarettes, smoked by most of the women in the study."Low-tar cigarettes are not low-risk cigarettes and ... more than half of those who smoke them will eventually be killed by them," the authors warned. The key causes of death among smokers were chronic lung disease, lung cancer, stroke and heart disease.

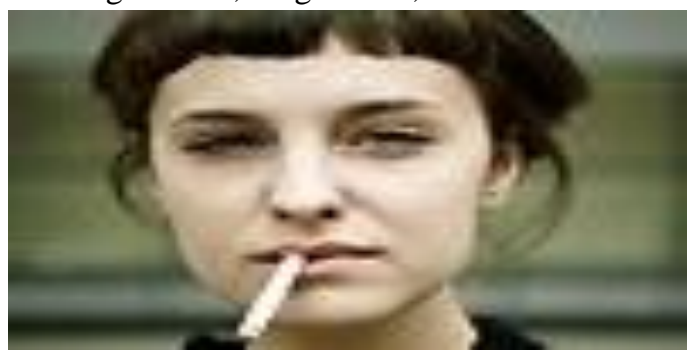




\section{E-CIGARETTE: IS GOOD ALTERNATIVE TO QUIT SMOKING OR BAD}

Smoking actually is a socially acceptable form of substance abuse that causes more deaths than more vilified ones like alcohol, cocaine, crystal meth and other recreational drugs. Cigarettes contain over a dozen carcinogens and 1 out of every 3 cancer-related deaths is caused due to use of tobacco products. Smokers even whilst accepting the hazardous effects of smoking simply don't have the will power or gumption to quit. There are various smoking cessation methods that help smokers quit including nicotine patches, gums and e-cigarettes where the underlying principle is to give addicts the nicotine "kick" without the harmful carcinogens found in tobacco. The most popular one is the electronic cigarette or the E-cig.

What's an e-cig?

An electronic cigarette is a device that mimics the entire smoking process by producing a mist which has the same sensation (sometimes the same flavour too) of smoking. The concept of an electronic cigarette has been around since the 60s but tobacco consumption wasn't really considered hazardous back then and it took until 2003 for the first smokeless e-cigarette to hit the market. Electronic Cigarettes manufacturers claim that they are like real cigarettes except that there are no hazardous health implications because there is no combustion, no tobacco and no smoking. Also since there is no passive smoking, second hand smoke and pollution due to butt litter or smoke.

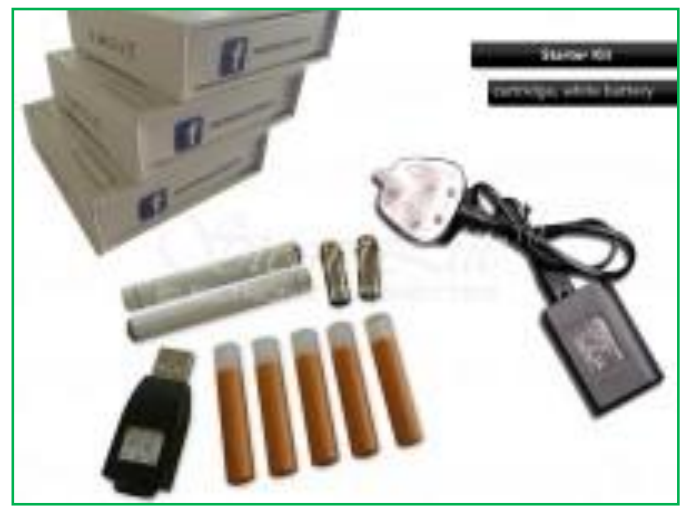

\section{What's in an e-cig?}

The e-cigarette basically consists of three parts: Cartridge, Atomizer and Power supply. The cartridge's a mouthpiece (like a cigarette's butt) that usually holds the liquid that is to be vaporized. The atomizer serves as a heating element and vaporizes the liquid and each of them contains a power supply like a chargeable plug, USB drive or batteries. An e-cigarette produces nicotine infused vapour and though it looks like smoke is actually atomised air. Some e-cigs replace this nicotine vapour with other flavours like vanilla, chocolate, etc. though certain anti-smoking groups feel this could encourage minors to smoke. As a smoking cessation tool some manufactures even look to replicate the flavour of particular brands like Marlboro, Camel, etc.

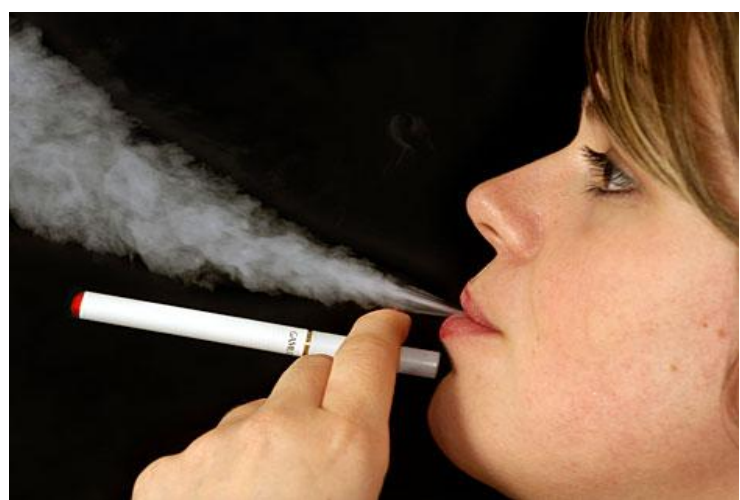

Are they really less harmful?

E-cigs are primary used as a smoking replacement or a smoking cessation device to help smokers quit though the lack of studies and its relative novelty make it hard to judge its health effects. According to United States Food and Drug Administration (FDA), known carcinogens were detected into the nicotine-cartridges and there were also concerns it could be marketed to younger people. However FDA methods have been derided in various journals for lack of evidence and which claimed that the nicotine content was a lot lower than actual cigarettes as were the health hazards. The World Health Organization (WHO) on the other hand have voiced their opinion that though e-cigs are usually marketed as devices for nicotine replacement therapy there were no studies to back up that claim and has refused to endorse the device. Research carried out at the University of 
East London suggests that nicotine content doesn't seem to be of central importance but other smoking related mannerisms like taste, vapour resembling smoke and hand movements helps reduce discomfort related with tobacco abstinence in the short term. In an online survey conducted by the University of Alberta, School of Public Health in 2009 among 303 smokers, it was found that e-cigarette substitution for tobacco cigarettes resulted in reduced health problems, the kind that usually ails smokers (less cough, improved ability to exercise, -improved sense of taste and smell).

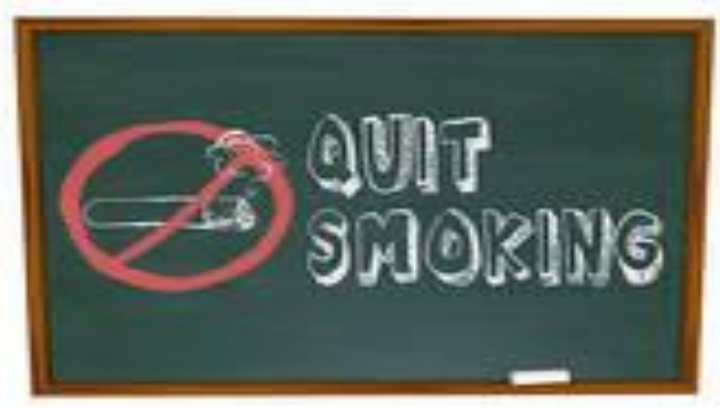

\section{CONCLUSION}

Women smokers can earn themselves 10 years of extra life by quitting the habit before middle age. A study of 1.3 million women found that smoking tripled the chances of dying over nine years compared with nonsmokers. Most of the increased death rate resulted from smoking-related diseases such as lung cancer, chronic lung disease, heart disease or stroke. The risk rose steeply with the quantity of tobacco smoked, but even light smokers who puffed fewer than 10 cigarettes a day doubled their likelihood of dying. Smokers who kicked the habit around age 30 avoided $97 \%$ of their excess risk of premature death. The authors of the Million Women Study wrote in The Lancet medical journal: Smokers lose at least 10 years of lifespan. Although the hazards of smoking until age 40 years and then stopping are substantial, the hazards of continuing are 10 times greater. Women aged 50 to 65 were enrolled into the study, designed to investigate links between health and lifestyle, from 1996 to 2001.Participants completed a questionnaire about living habits, medical and social factors and were re-surveyed three years later. Women were monitored for a total of 12 years on average, during which there were 66,000 deaths. Initially, $20 \%$ of the women were smokers, $28 \%$ were ex-smokers, and $52 \%$ had never smoked. Those who still smoked at the three year re-survey were almost three times more likely than nonsmokers to die over the next nine years. Both the hazards of smoking and the benefits of quitting were greater than previous studies had suggested, said the researchers. If women smoke like men, they die like men - but, whether they are men or women, smokers who stop before reaching middle age will on average gain about an extra 10 years of life: Both in the UK and in the USA, women born around 1940 were the first generation in which many smoked substantial numbers of cigarettes throughout adult life. Hence, only in the 21st century could we observe directly the full effects of prolonged smoking, and of prolonged cessation, on premature mortality among women. "In most of Europe and the USA, the popularity of smoking among young women reached its peak in the 1960s, decades later than for men. Hence, previous studies have underestimated the full eventual impact of smoking on mortality in women, simply because of the lengthy time lag between smoking uptake by young women and disease onset in middle and old age."Although there isn't conclusive evidence to suggest that e-cigs are completely harmless at least all the research studies suggest that they and are definitely less harmful than traditional cigarettes. They also provide smokers with the means to quit by mimicking the mannerisms of long time users right from the hand movements, inhaling and the atomised vapour that imitates smoke.

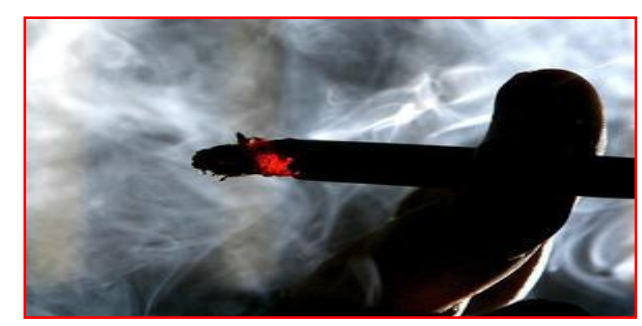

\section{REFERENCES}

http://en.wikipedia.org/wiki/Electronic_cigarette

http://www.naturalmedicine.com/news/community-news/surprise-e-cigarettes-dangerous/ http://www.smokelessdelite.com/blog/e-cigarettes-dangers

http://www.thesafecig.com/what-is-an-electronic-cigarette.php

Sinha, S. October 27, 2012. Times Nation; TOI, p.7. New Delhi 